RECK, Janriê Rodrigues; HÜBNER, Bruna Henrique. A transformação digital do estado: digitalização do governo e dos serviços públicos no Brasil. Revista Eletrônica Direito e Política, Programa de Pós-Graduação Stricto Sensu em Ciência Jurídica da UNIVALI, Itajaí, v.16, n.3, 30 quadrimestre de 2021. Disponível em: www.univali.br/direitoepolitica - ISSN 1980-7791.

\title{
A TRANSFORMAÇÃO DIGITAL DO ESTADO: DIGITALIZAÇÃO DO GOVERNO E DOS SERVIÇOS PÚBLICOS NO BRASIL
}

\author{
THE DIGITAL TRANSFORMATION OF THE STATE: DIGITALIZATION OF THE \\ GOVERNMENT AND PUBLIC SERVICES IN BRAZIL
}

Janriê Rodrigues Reck ${ }^{1}$

Bruna Henrique Hübner ${ }^{2}$

\section{RESUMO}

A Estratégia de Governo Digital para o período de 2020 a 2022 objetiva a transformação do governo por meio de tecnologias digitais e busca oferecer mais eficiência nas políticas públicas e serviços públicos. Considerando que o objetivo é tornar o governo mais dinâmico, mais próximo da população e mais eficiente para resolver problemas e facilitar a vida do cidadão, busca-se responder: quais foram as principais medidas adotados na busca pela concretização da transformação digital do governo e dos serviços públicos no Brasil? A pesquisa adota o método dedutivo e a técnica de pesquisa bibliográfica, por meio de documentação indireta. O processo de inserção de Tecnologias da Informação e Comunicação (TIC) na administração pública brasileira remonta a década de 1990 e, conclui-se que, atualmente, a Lei n. ${ }^{\circ} 14.129 / 2021$ pode ser vista como importante mecanismo da transformação digital do governo e dos serviços públicos no Brasil.

PALAVRAS-ChAVE: Governo Digital; Serviço Público; Transformação digital; Tecnologias de Informação e Comunicação (TICs).

\section{ABSTRACT}

The Digital Government Strategy for the period 2020 to 2022 aims to transforming the government through digital technologies and seeks to offer more efficiency in public policies and public services. Considering that the objective is to make the government more dynamic, closer to the population and more efficient in solving problems and making life easier for citizens, we seek to answer: what were the

\footnotetext{
${ }^{1}$ Santa Cruz do Sul, Rio Grande do Sul. Brasil. Professor do Programa de Pós-Graduação, Mestrado e Doutorado da Universidade de Santa Cruz do Sul. Procurador Federal. E-mail: janriereck@unisc.br

2 Santa Cruz do Sul, Rio Grande do Sul. Brasil. Mestranda no Programa da Pós-Graduação em Direito

- Mestrado e Doutorado da Universidade de Santa Cruz do Sul (UNISC), com bolsa PROSUC/CAPES.

E-mail: bruna.hubner@outlook.com
} 
RECK, Janriê Rodrigues; HÜBNER, Bruna Henrique. A transformação digital do estado: digitalização do governo e dos serviços públicos no Brasil. Revista Eletrônica Direito e Política, Programa de Pós-Graduação Stricto Sensu em Ciência Jurídica da UNIVALI, Itajaí, v.16, n.3, 30 quadrimestre de 2021. Disponível em: www.univali.br/direitoepolitica - ISSN 1980-7791.

main measures adopted in the search for the implementation of the digital transformation of government and public services in Brazil? The research adopts the deductive method and the bibliographic research technique, through indirect documentation. The process of insertion of Information and Communication Technologies (ICT) in the Brazilian public administration dates back to the 1990s and, it is concluded that, currently, Law No. 14.129/2021 can be seen as an important mechanism for the government's digital transformation and public services in Brazil.

KEYWORDS: Digital Government; Public service; Digital transformation; Information and Communication Technologies (ICTs).

\section{INTRODUÇÃO}

No Brasil, em 2016 foi instituída a Estratégia de Governança Digital (EGD), que foi atualizada em 2020. Propõe a promoção do uso pelo setor público de recursos de tecnologia da informação para melhorar a disponibilização de informação, incentivar a participação da sociedade no processo de tomar de decisão e aprimorar o nível de transparência e efetividade do governo federal.

Em 2018 foi publicada a Estratégia Brasileira para a Transformação Digital (EDigital), iniciativa do Governo Federal, coordenada pelo Ministério da Ciência, Tecnologia, Inovações e Comunicações, basicamente consiste em uma proposta de estratégia de longo prazo para a economia digital. Dito de outra forma, uma política pública a ser implementada. Possui previsão normativa no Decreto no 9.319, de 21 de março de 2018, que institui o Sistema Nacional para a Transformação Digital e estabelece a estrutura de governança para a implantação da Estratégia Brasileira para a Transformação Digital.

O Decreto no 10.332, publicado no dia 29 de abril de 2020, instituiu a Estratégia de Governo Digital para o período de 2020 a 2022, no âmbito dos órgãos e das entidades da administração pública federal direta, autárquica e fundacional e dá outras providências. A Estratégia de Governo Digital para o período de 2020 a 2022 organiza-se em princípios, objetivos e iniciativas para a transformação do governo por meio de tecnologias digitais e busca oferecer mais eficiência nas políticas públicas e serviços, bem como tornar mais simplificado o acesso. 
RECK, Janriê Rodrigues; HÜBNER, Bruna Henrique. A transformação digital do estado: digitalização do governo e dos serviços públicos no Brasil. Revista Eletrônica Direito e Política, Programa de Pós-Graduação Stricto Sensu em Ciência Jurídica da UNIVALI, Itajaí, v.16, n.3, 30 quadrimestre de 2021. Disponível em: www.univali.br/direitoepolitica - ISSN 1980-7791.

Considerando que o objetivo é tornar o governo mais dinâmico, mais próximo da população e mais eficiente para resolver problemas e facilitar a vida do cidadão, busca-se responder: quais foram as principais medidas adotados na busca pela concretização da transformação digital do governo e dos serviços públicos no Brasil?

A pesquisa adota o método dedutivo e a técnica de pesquisa bibliográfica, por meio de documentação indireta.

\section{O PAPEL DO ESTADO NA TRANSFORMAÇÃO DIGITAL}

A relação que o Estado possui com a tecnologia pode ser um dos fatores determinantes para o nível de desenvolvimento tecnológico de determinada sociedade, contudo, "a dependência exclusiva do Estado tem um preço, e o preço para a China foi atraso, fome, epidemias, dominação colonial e guerra civil até, pelo menos, meados do século $\mathrm{XX}^{\prime \prime 3}$.

Ao longo da história da humanidade percebe-se que a habilidade (ou falta dela) das sociedades dominarem a tecnologia, principalmente aquelas que são estratégicas em cada época, "traça seu destino a ponto de podermos dizer que, embora não determine a evolução histórica e a transformação social, a tecnologia (ou sua falta) incorpora a capacidade de transformação das sociedades"4.

Atualmente, o Estado continua sendo importante na estruturação de estratégias e no fomento do setor de tecnologia, ainda mais em países onde esse é insipiente ou encontra-se em desenvolvimento. Ainda, "As rápidas transformações na economia e na sociedade proporcionadas pelo ambiente digital impõem novos desafios à atuação do governo" 5 .

${ }^{3}$ CASTELLS, Manuel. A sociedade em rede - A era da informação: economia, sociedade e cultura. 8 ed. rev. e ampl. Tradução: Roneide Venâncio Majer. São Paulo: Paz e Terra, 2005, p. 47.

${ }^{4}$ CASTELLS, Manuel. A sociedade em rede - A era da informação: economia, sociedade e cultura. 8 ed. rev. e ampl. Tradução: Roneide Venâncio Majer. São Paulo: Paz e Terra, 2005, p. 45.

5 BRASIL. Estratégia brasileira para a transformação digital (E-Digital). Brasília, 2018, p. 06. 
RECK, Janriê Rodrigues; HÜBNER, Bruna Henrique. A transformação digital do estado: digitalização do governo e dos serviços públicos no Brasil. Revista Eletrônica Direito e Política, Programa de Pós-Graduação Stricto Sensu em Ciência Jurídica da UNIVALI, Itajaí, v.16, n.3, 30 quadrimestre de 2021. Disponível em: www.univali.br/direitoepolitica - ISSN 1980-7791.

Para Castells, a tecnologia não determina a sociedade, tampouco é a sociedade que escolhe e/ou determina

O curso da transformação tecnológica "uma vez que muitos fatores, inclusive criatividade e iniciativa empreendedora, intervêm no processo de descoberta científica, inovação tecnológica e aplicações sociais, de forma que o resultado final depende de um complexo padrão interativo" ${ }^{\prime 6}$.

Nesse sentido, o determinismo tecnológico defendido por Thorstein Veblen no século XIX, "não é o que basta para que a sociedade floresça, como que num mundo em que as exigências sociais e políticas não se conformem como fatores essenciais para o seu prosseguimento"7.

Contudo, embora não determine a tecnologia, a sociedade pode limitar seu desenvolvimento e o Estado tem papel fundamental nesse processo. Assim, "principalmente pela intervenção estatal, a sociedade pode entrar num processo acelerado de modernização tecnológica capaz de mudar o destino das economias, do poder militar e do bem-estar social em poucos anos" ${ }^{\prime \prime}$.

Ao longo da história, "as sociedades evoluíram de padrões de organização simples, como as tribos de coletores e caçadores, e posteriormente as aldeias rurais, para padrões mais complexos que originaram as vilas, e depois as cidades" ${ }^{\prime 9}$. Esses ciclos de evolução foram motivados para ou pelo surgimento de tecnologias, como por exemplo, aquedutos em Roma, sistema de esgoto em Londres, motores a vapor ou elétricos, lâmpadas, rádio, automóvel e assim tantas outras que em seu tempo "buscaram atender as demandas mais elementares das sociedades,

${ }^{6}$ CASTELLS, Manuel. A sociedade em rede - A era da informação: economia, sociedade e cultura. 8 ed. rev. e ampl. Tradução: Roneide Venâncio Majer. São Paulo: Paz e Terra, 2005, p. 47.

7 WEISS, Marcos Cesar. Sociedade sensoriada: a sociedade da transformação digital. Estudos Avançados [online]. 2019, v. 33, n. 95. Disponível em: https://doi.org/10.1590/s01034014.2019.3395.0013.ISSN 1806-9592.Acesso em 09 ago 2021.

8 CASTELLS, Manuel. A sociedade em rede - A era da informação: economia, sociedade e cultura. 8 ed. rev. e ampl. Tradução: Roneide Venâncio Majer. São Paulo: Paz e Terra, 2005, p. 44.

9 WEISS, Marcos Cesar. Sociedade sensoriada: a sociedade da transformação digital. Estudos Avançados [online]. 2019, v. 33, n. 95. Disponível em: https://doi.org/10.1590/s01034014.2019.3395.0013.ISSN 1806-9592.Acesso em 09 ago 2021, p. 203. 
RECK, Janriê Rodrigues; HÜBNER, Bruna Henrique. A transformação digital do estado: digitalização do governo e dos serviços públicos no Brasil. Revista Eletrônica Direito e Política, Programa de Pós-Graduação Stricto Sensu em Ciência Jurídica da UNIVALI, Itajaí, v.16, n.3, 30 quadrimestre de 2021. Disponível em: www.univali.br/direitoepolitica - ISSN 1980-7791.

moldaram o que somos hoje, criando, promovendo e fortalecendo diferentes formas de socialização"10.

Vive-se agora uma época de profundas mudanças sociais e tecnológicas, ligadas principalmente ao desenvolvimento e interesse nas Tecnologias da Informação e Comunicação (TIC). Atualmente, vive-se o se denomina por transformação digital, que traz profundas mudanças para a sociedade, pois a cultura digital cria um novo cenário de participação social, cultural, profissional, etc., e também nova demandas surgem. Esse novo cenário pode ser observado nos seguintes exemplos:

A economia deixa de operar em tempo parcial para se transformar em uma economia que opera 24 horas por dia, durante sete dias por semana. Governos passam a estar sob influência e vigilância direta da sociedade local e global, sendo constantemente percebidos, avaliados e desafiados em suas estruturas institucionais, políticas e sociais, para além da publicidade que podem e devem dar sobre suas decisões particulares e multilaterais. A cultura tem suas normas e valores coletivos expostos, dando publicidade às escolhas que são feitas em termos de identidade e convicções. As pessoas, particularmente, são confrontadas com situações de incerteza em quaisquer dimensões da vida, mesmo quando isso envolve suas opções de vida afetiva ou suas opiniões e escolhas políticas ${ }^{11}$.

O Estado brasileiro possui papel fundamental na transformação digital da economia e da sociedade, que perpassa pela digitalização dos serviços públicos e do governo, buscando aumentar a eficiência da atividade governamental, tanto em termos de custos ou de maior racionalização, como em relação ao aumento da participação social ou da satisfação do cidadão, visando principalmente a melhoria da prestação serviços à população ${ }^{12}$. Em uma sociedade em desenvolvimento, como no caso

10 WEISS, Marcos Cesar. Sociedade sensoriada: a sociedade da transformação digital. Estudos Avançados [online]. 2019, v. 33, n. 95. Disponível em: https://doi.org/10.1590/s01034014.2019.3395.0013.ISSN 1806-9592.Acesso em 09 ago 2021, p. 203.

11 WEISS, Marcos Cesar. Sociedade sensoriada: a sociedade da transformação digital. Estudos

Avançados [online]. 2019, v. 33, n. 95. Disponível em: https://doi.org/10.1590/s01034014.2019.3395.0013.ISSN 1806-9592.Acesso em 09 ago 2021, p. 204.

12 BRASIL. Estratégia brasileira para a transformação digital (E-Digital). Brasília, 2018. 
RECK, Janriê Rodrigues; HÜBNER, Bruna Henrique. A transformação digital do estado: digitalização do governo e dos serviços públicos no Brasil. Revista Eletrônica Direito e Política, Programa de Pós-Graduação Stricto Sensu em Ciência Jurídica da UNIVALI, Itajaí, v.16, n.3, 30 quadrimestre de 2021. Disponível em: www.univali.br/direitoepolitica - ISSN 1980-7791.

brasileiro a inovação governamental depende não apenas de inovações, propriamente ditas, mas, em grande medida, da conjugação dessas com melhorias incrementais, cujos resultados criem condições de legitimação social e, com isso, permanência e realimentação positiva do processo ${ }^{13}$.

Contudo, as tecnologias digitais operam de forma dupla em relação ao Estado, pios "ao mesmo tempo em que potencializam ganhos de eficiência e novos e melhores serviços, ameaçam a capacidade de coordenação social do Estado, caso ele não acompanhe as demandas sociais que Ihe são dirigidas"14.

Em resumo, o Estado, por se tratar da entidade que organiza e reflete sobre a sociedade como um todo, não pode ficar indiferente as mudanças e novas demandas advindas do desenvolvimento e incorporação das tecnologias pela sociedade como um todo.

Para o funcionamento do Estado, nos países em desenvolvimento, a massificação das tecnologias da informação e comunicação (TIC) deve ser vista como oportunidade para uma rápida transição a um novo paradigma. Partindo de uma situação de grande irracionalidade, corrupção e cultura de desorganização, a possibilidade de saltos qualitativos, com a adoção de algumas medidas estratégicas, é maior, se comparada à possibilidade de evolução das democracias maduras nesse sentido ${ }^{15}$.

Ainda, os investimentos em TICs contribuem para o desenvolvimento econômico e para a redução das desigualdades, pois possibilitam a habilitação das "pessoas à participação ativa na sociedade, desde que esteja presente um arcabouço legal

13 BUCCI, Maria Paula Dallari. Fundamentos para uma Teoria Jurídica das Políticas Públicas. São Paulo: Saraiva, 2013, p. 24-25.

14 BRASIL. Estratégia brasileira para a transformação digital (E-Digital). Brasília, 2018, p. 93.

15 BUCCI, Maria Paula Dallari. Fundamentos para uma Teoria Jurídica das Políticas Públicas. São Paulo: Saraiva, 2013, p. 23. 
RECK, Janriê Rodrigues; HÜBNER, Bruna Henrique. A transformação digital do estado: digitalização do governo e dos serviços públicos no Brasil. Revista Eletrônica Direito e Política, Programa de Pós-Graduação Stricto Sensu em Ciência Jurídica da UNIVALI, Itajaí, v.16, n.3, 30 quadrimestre de 2021. Disponível em: www.univali.br/direitoepolitica - ISSN 1980-7791.

capaz de proteger os direitos a liberdade de expressão, liberdade de informação e um ambiente regulatório de proteção à privacidade"16.

Além disso, a velocidade com que as TICs têm evoluído e intensificado o dinamismo das estruturas sociais, "alimenta com um salutar sentido de urgência e inovação a vida política de um país que modifica muito morosa e gradualmente seu panorama institucional, pano de fundo de exclusão social e conformismo"17.

A melhoria e modernização dos serviços públicos e da infraestrutura, os incentivos à produção e à inovação, bem como as políticas de inclusão social e todas as iniciativas de longo prazo, dependem não apenas da compreensão dos papéis do Estado e do governo, mas também do domínio técnico dos seus mecanismos de funcionamento, tanto no nível das relações políticas tradicionais como nas implicações dessas com a execução das decisões e dos dispêndios governamentais ${ }^{18}$.

No entanto, no setor público não basta apenas a introdução de tecnologias para o aperfeiçoamento pontual de processos e serviços, "é necessária a estruturação de um ecossistema digital que simplifique e facilite as interações entre Estado e os demais atores sociais"19. Assim, o Governo Digital tem como fundamento central a geração de valor público para a sociedade por meio da utilização das tecnologias da informação e da comunicação ${ }^{20}$.

16 WEISS, Marcos Cesar. Sociedade sensoriada: a sociedade da transformação digital. Estudos Avançados [online]. 2019, v. 33, n. 95. Disponível em: https://doi.org/10.1590/s01034014.2019.3395.0013.ISSN 1806-9592.Acesso em 09 ago 2021, p. 206.

17 BUCCI, Maria Paula Dallari. Fundamentos para uma Teoria Jurídica das Políticas Públicas. São Paulo: Saraiva, 2013, p. 23.

18 BUCCI, Maria Paula Dallari. Fundamentos para uma Teoria Jurídica das Políticas Públicas. São Paulo: Saraiva, 2013, p. 25.

${ }^{19}$ BRASIL. Estratégia brasileira para a transformação digital (E-Digital). Brasília, 2018, p. 93.

${ }^{20}$ BRASIL. Estratégia brasileira para a transformação digital (E-Digital). Brasília, 2018. 
RECK, Janriê Rodrigues; HÜBNER, Bruna Henrique. A transformação digital do estado: digitalização do governo e dos serviços públicos no Brasil. Revista Eletrônica Direito e Política, Programa de Pós-Graduação Stricto Sensu em Ciência Jurídica da UNIVALI, Itajaí, v.16, n.3, 30 quadrimestre de 2021. Disponível em: www.univali.br/direitoepolitica - ISSN 1980-7791.
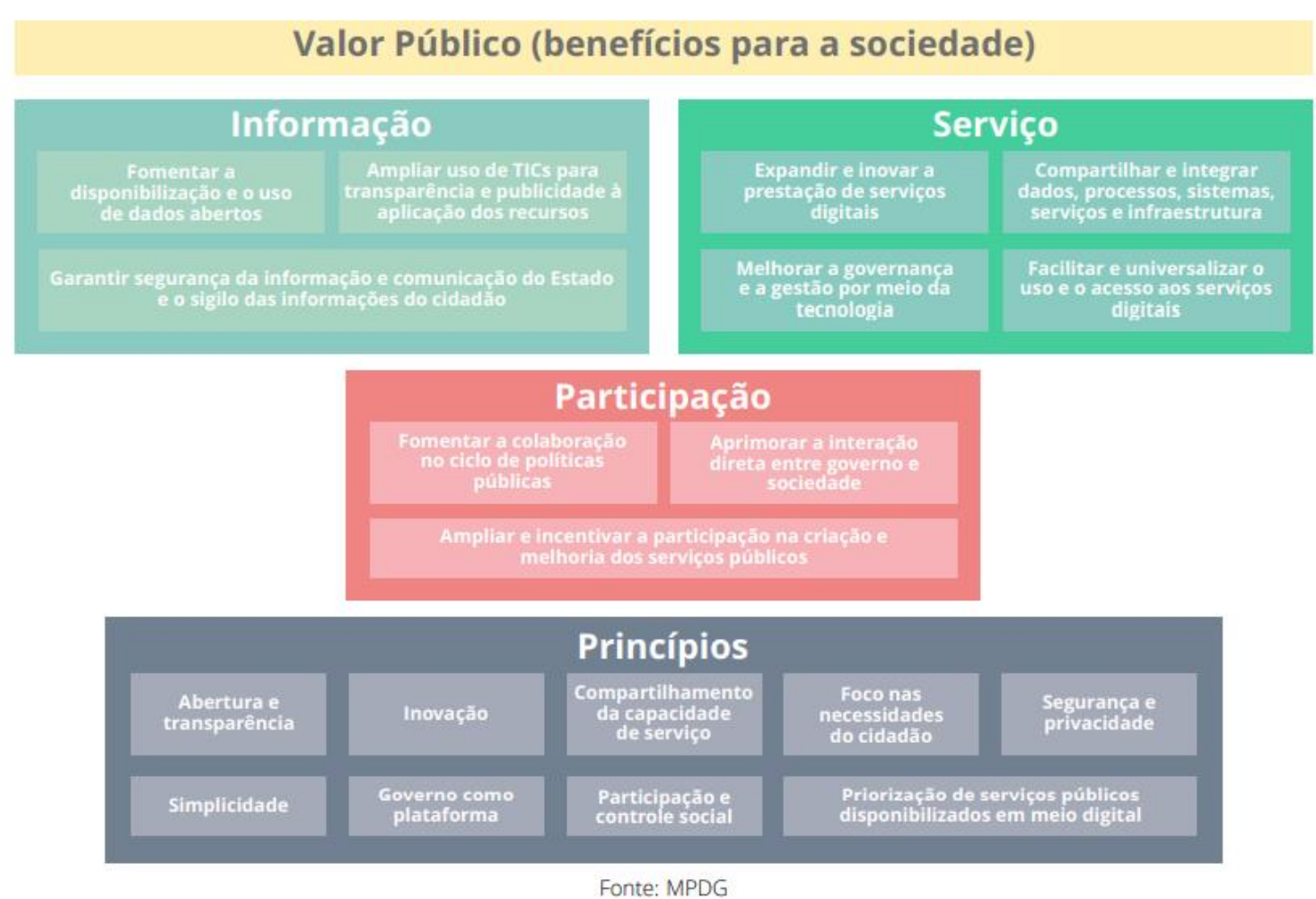

Nesse contexto, a Estratégia Brasileira para a Transformação Digital (E-Digital), iniciativa do Governo Federal, coordenada pelo Ministério da Ciência, Tecnologia, Inovações e Comunicações, basicamente consiste em uma proposta de estratégia de longo prazo para a economia digital. Dito de outra forma, uma política pública a ser implementada.

Existem ao menos três grandes linhas orientadoras para as políticas públicas na área de cidadania e governo digital. A tecnologia digital deverá ser utilizada para "i) aumentar a transparência e controle social das atividades estatais, ii) ampliar a participação social na formulação das políticas públicas, e iii) prover mais e melhores serviços públicos digitais"21.

${ }^{21}$ BRASIL. Estratégia brasileira para a transformação digital (E-Digital). Brasília, 2018, p. 93. 
RECK, Janriê Rodrigues; HÜBNER, Bruna Henrique. A transformação digital do estado: digitalização do governo e dos serviços públicos no Brasil. Revista Eletrônica Direito e Política, Programa de Pós-Graduação Stricto Sensu em Ciência Jurídica da UNIVALI, Itajaí, v.16, n.3, 30 quadrimestre de 2021. Disponível em: www.univali.br/direitoepolitica - ISSN 1980-7791.

Além desses pilares, para a formulação das ações voltadas ao atingimento das dimensões citadas, os gestores da política pública devem se preocupar com os quatro tipos principais de desafios enfrentados pelo cidadão excluído digitalmente 22 :

\begin{tabular}{|c|c|}
\hline A) ACESSO & B) HABILIDADES \\
\hline $\begin{array}{l}\text { refere-se à } \\
\text { capacidade } \\
\text { de realmente } \\
\text { ir on-line e } \\
\text { conectar-se à } \\
\text { internet, estando } \\
\text { relacionado a } \\
\text { diversos fatores, } \\
\text { como política } \\
\text { de preços, } \\
\text { condiçőes } \\
\text { de renda da } \\
\text { populaçăo e } \\
\text { limitaçőes da } \\
\text { infraestrutura; }\end{array}$ & $\begin{array}{l}\text { relacionado a } \\
\text { aspectos de } \\
\text { formação e } \\
\text { competênciã } \\
\text { dos indivíduos, } \\
\text { mas que } \\
\text { ultrapassa } \\
\text { a simples } \\
\text { capacitação } \\
\text { especifica para } \\
\text { utilização das } \\
\text { TIC. abrangendo } \\
\text { questőes como o } \\
\text { nível de instrução } \\
\text { da população, } \\
\text { que afeta sua } \\
\text { capacidade } \\
\text { dc usar as } \\
\text { tecnologias de } \\
\text { informação e } \\
\text { comunicação; }\end{array}$ \\
\hline
\end{tabular}

C) MOTIVAÇÃO

relacionado às dimensð̃es da alfabetizaçăo e conteúdo, este desafio referese à motivaçăo do indivíduo em querer utilizar as TIC, ou seja, ter conhecimento das vantagens e da potencialidade dessas novas tecnologias para o seu desenvolvimento pessoal;
D) CONFIANÇA

refere-se a aspectos da segurança da informaçăo. como, por exemplo, o receio do indivíduo de ter seus dados e informaçōes violados, indo até a questőes psicológicas, como o receio do erro, năo saber por onde começar ou sua incapacidadc individual.

O principal objetivo da Estratégia de Governança Digital é desburocratizar, modernizar, fortalecer e simplificar a relação do Estado com a sociedade, utilizando tecnologias digitais. Seus princípios incluem a abertura e transparência, priorização de serviços públicos disponibilizados em meio digital, compartilhamento da capacidade de serviço, foco nas necessidades do cidadão, segurança e privacidade, simplicidade, participação e controle social, governo com plataforma e inovação.

22 BRASIL. Tribunal de Contas da União. Política pública de inclusão digital/Tribunal de Contas da União, Brasília: TCU, SeinfraAeroTelecom, 2015, p. 20. 
RECK, Janriê Rodrigues; HÜBNER, Bruna Henrique. A transformação digital do estado: digitalização do governo e dos serviços públicos no Brasil. Revista Eletrônica Direito e Política, Programa de Pós-Graduação Stricto Sensu em Ciência Jurídica da UNIVALI, Itajaí, v.16, n.3, 30 quadrimestre de 2021. Disponível em: www.univali.br/direitoepolitica - ISSN 1980-7791.

A Revisão do Governo Digital do Brasil, realizada pela Organização para a Cooperação e Desenvolvimento Econômico (OCDE), busca auxiliar o governo brasileiro em seus esforços de transição de uma abordagem de governo eletrônico (e-government) para um governo digital, trilhando o caminho para a transformação digital sustentável do setor público. Segundo a Revisão, seis são as dimensões do governo digital e da mudança de governo eletrônico para o governo digital: parte-se de uma administração centrada no usuário para uma administração conduzida pelo usuário; de um governo reativo a proativo na elaboração de políticas públicas e prestação de serviços; de um governo centrado na informação para um setor público orientado por dados; da digitalização de processos existentes ao processo por concepção digital (digital by design); de um governo provedor de serviços para um governo como plataforma para cocriação de valor público e o acesso à informação para abertura como padrão (open by default $)^{23}$.

Como referido acima, é necessário sair do mero consumo de tecnologias para a imersão no meio digital como um modo de gerir, prestar serviços e aprimorar o exercício da cidadania, passar do "governo eletrônico" para o Governo Digital, "que representa um novo paradigma para os serviços públicos brasileiros, a ser aplicado considerando uma dimensão experimental da ação administrativa"24.

O uso das TICs nos serviços públicos constrói uma tendência disruptiva em relação ao modelo de Governo eletrônico, de modelagem tecnológica predominantemente incremental, de forma a avançar para um paradigma de uso de tecnologias como instrumentos de densificação de direitos sociais ${ }^{25}$.

23 OCDE. Digital Government Review of Brazil: Towards the Digital Transformation of the Public Sector. OECD Digital Government Studies, OECD Publishing, 2018, Paris. Disponível em: https://doi. org/10.1787/9789264307636-en. Acesso em: jul. 2021.

24 CRISTÓVAM, José Sérgio da Silva; SAIKALI, Lucas Bossoni; SOUSA, Thanderson Pereira de. Governo Digital na Implementação de Serviços Públicos para a Concretização de Direitos Sociais no Brasil. Sequência, Florianópolis, n. 84, p. 209-242, abr. 2020. DOI: 10.5007/21777055.2020v43n89p209, p. 217

25 CRISTÓVAM, José Sérgio da Silva; SAIKALI, Lucas Bossoni; SOUSA, Thanderson Pereira de. Governo Digital na Implementação de Serviços Públicos para a Concretização de Direitos Sociais no Brasil. Sequência, Florianópolis, n. 84, p. 209-242, abr. 2020. DOI: 10.5007/21777055.2020v43n89p209, p. 217. 
RECK, Janriê Rodrigues; HÜBNER, Bruna Henrique. A transformação digital do estado: digitalização do governo e dos serviços públicos no Brasil. Revista Eletrônica Direito e Política, Programa de Pós-Graduação Stricto Sensu em Ciência Jurídica da UNIVALI, Itajaí, v.16, n.3, 30 quadrimestre de 2021. Disponível em: www.univali.br/direitoepolitica - ISSN 1980-7791.

Embora a digitalização do governo e de serviços públicos já estivesse em curso, a pandemia da COVID-19 contribuiu para o aceleramento desse processo. Com a crise sanitária, a onda de digitalização passou a ser mais necessária.

\section{DIGITALIZAÇÃO DO GOVERNO E DOS SERVIÇOS PÚBLICOS NO BRASIL}

A Administração Pública brasileira, desde a reforma administrativa da década de $1990^{26}$, passou a empregar as TICs como forma de consolidação do Governo eletrônico, especialmente em sua rotina burocrática e na promoção/ampliação de acesso à informação 27.

Os primeiros serviços eletrônicos pelas administrações públicas datam do fim da década de 1980. Como políticas públicas dos governos, a inserção das TICS se deu a partir da década de 90, de modo gradual e em um aspecto global. De todo modo, a literatura relata que foi a disseminação do comércio eletrônico que impulsionou o desenvolvimento da concepção do governo eletrônico, que se referira ao uso das tecnologias pelos governos ${ }^{28}$.

Em 2020 houve a atualização da Estratégia de Governança Digital (EGD), que foi instituída em 2016, propõem promover o uso pelo setor público de recursos de tecnologia da informação para melhorar a disponibilização de informação, incentivar a participação da sociedade no processo de tomar de decisão e

26 A lógica de inserção das TICs no Brasil, seguindo o movimento de reforma administrativa, é resultante da crise fiscal da década de 1980 e do enfraquecimento de um modelo de gestão extremamente burocrático. Nessa esteira, o modelo de Administração gerencial, implantado sob a justificativa de melhorar os resultados da gestão e prestar serviços de qualidade para os cidadãos, concebe o uso de tecnologias como ferramenta indispensável. CRISTÓVAM, José Sérgio da Silva; SAIKALI, Lucas Bossoni; SOUSA, Thanderson Pereira de. Governo Digital na Implementação de Serviços Públicos para a Concretização de Direitos Sociais no Brasil. Sequência, Florianópolis, n. 84, p. 209-242, abr. 2020. DOI: 10.5007/2177-7055.2020v43n89p209.

27 CRISTÓVAM, José Sérgio da Silva; SAIKALI, Lucas Bossoni; SOUSA, Thanderson Pereira de. Governo Digital na Implementação de Serviços Públicos para a Concretização de Direitos Sociais no Brasil. Sequência, Florianópolis, n. 84, p. 209-242, abr. 2020. DOI: 10.5007/21777055.2020v43n89p209.

28 VIANA, Ana Cristina Aguilar. Transformação digital na administração pública: do governo eletrônico ao governo digital. Revista Eurolatinoamericana de Derecho Administrativo, Santa Fe, vol. 8 , n. 1 , p. 115-136, ene./jun. 2021, p.117-118. 
RECK, Janriê Rodrigues; HÜBNER, Bruna Henrique. A transformação digital do estado: digitalização do governo e dos serviços públicos no Brasil. Revista Eletrônica Direito e Política, Programa de Pós-Graduação Stricto Sensu em Ciência Jurídica da UNIVALI, Itajaí, v.16, n.3, 30 quadrimestre de 2021. Disponível em: www.univali.br/direitoepolitica - ISSN 1980-7791.

aprimorar o nível de transparência e efetividade do governo federal. A EGD está normatizada no decreto no 10.332, de 28 de abril de 2020.

$\mathrm{Na}$ pesquisa sobre Governo Eletrônico 2020, publicada pela Organização das Nações Unidas (ONU), o Brasil ocupa a $20^{\circ}$ posição, entre 193 países, com melhor oferta de serviços públicos digitais e ficou em primeiro lugar neste quesito na América do Sul e em segundo nas Américas, à frente de países como Canadá, Chile e Uruguai e atrás somente dos Estados Unidos ${ }^{29}$.

De acordo com a ONU, o Índice de Serviços Online mede o uso de tecnologia da informação e comunicações (TIC) pelos governos para a prestação de serviços públicos em nível nacional, incluindo dados abertos, participação eletrônica, prestação de serviços multicanais, serviços móveis, nível de utilização pelo cidadão, bem como parcerias inovadoras por meio do uso de TICs. O líder mundial na oferta de serviços on-line é a Coreia do Sul, seguida por Estônia, Dinamarca e Finlândia ${ }^{30}$.

Segundo o Ministério da Economia, o Governo Federal atingiu 1.000 serviços públicos digitalizados em menos de dois anos e popularizou o acesso on-line da população, facilitando e agilizando a solução de suas demandas. No ranking dos serviços mais acessados estão: Consultar restituição de imposto de renda; Sacar o Abono Salarial; Consultar CPF; Obter a Carteira de Trabalho; Emitir Certidão de Antecedentes Criminais e Realizar Inscrição no INSS. Ainda, é disponibilizada listas gerais com os serviços transformados por ano $(2019,2020 \text { e } 2021)^{31}$.

${ }^{29}$ GOV.BR. 2020. Governo eletrônico: ONU classifica Brasil entre os 20 países com melhor oferta de serviços públicos digitais. Notícias. Casa Civil, jul., 2020. Disponível em:https://www.gov.br/casacivil/pt-br/assuntos/noticias/2020/julho/governo-eletronico-onuclassifica-brasil-entre-os-20-paises-com-melhor-oferta-de-servicos-publicos-digitais. Acesso em: jul., 2021.

30 GOV.BR. 2020. Governo eletrônico: ONU classifica Brasil entre os 20 países com melhor oferta de serviços públicos digitais. Notícias. Casa Civil, jul., 2020. Disponível em:https://www.gov.br/casacivil/pt-br/assuntos/noticias/2020/julho/governo-eletronico-onuclassifica-brasil-entre-os-20-paises-com-melhor-oferta-de-servicos-publicos-digitais. Acesso em: jul., 2021.

${ }^{31}$ GOV.BR. 2020. Governo eletrônico: ONU classifica Brasil entre os 20 países com melhor oferta de serviços públicos digitais. Notícias. Casa Civil, jul., 2020. Disponível em:https://www.gov.br/casacivil/pt-br/assuntos/noticias/2020/julho/governo-eletronico-onu- 
RECK, Janriê Rodrigues; HÜBNER, Bruna Henrique. A transformação digital do estado: digitalização do governo e dos serviços públicos no Brasil. Revista Eletrônica Direito e Política, Programa de Pós-Graduação Stricto Sensu em Ciência Jurídica da UNIVALI, Itajaí, v.16, n.3, 30 quadrimestre de 2021. Disponível em: www.univali.br/direitoepolitica - ISSN 1980-7791.

Nesse cenário, em março de 2021 foi sancionada a Lei n. ${ }^{\circ}$ 14.129/2021 que dispõe sobre princípios, regras e instrumentos para o Governo Digital e para o aumento da eficiência pública, especialmente por meio da desburocratização, da inovação, da transformação digital e da participação do cidadão. A matéria é oriunda do Projeto de lei 317/21 (7843/17), aprovada pelo Congresso Nacional em fevereiro 2021.

A lei, também chamada de GovTech, pretende unificar o acesso do cidadão à serviços públicos e amplia o uso das assinaturas eletrônicas nas interações e comunicações entre órgãos públicos e entre esses e os cidadãos, entre outras inovações.

A lei se aplica aos (i) órgãos da administração pública direta federal dos três poderes, incluído o Tribunal de Contas da União e o Ministério Público da União; (ii) às entidades da administração pública indireta federal, incluídas as empresas públicas e sociedades de economia mista, suas subsidiárias e controladas, que prestem serviço público, autarquias e fundações públicas; e (iii) às administrações diretas e indiretas dos demais entes federados, nos termos dos itens (i) e (ii) descritos acima, desde que adotem os comandos da Lei por meio de atos normativos próprios ${ }^{32}$.

Acerca do serviço público digital, a lei em seu artigo $4^{\circ}$ define conceitos, como os de autosserviço (acesso pelo cidadão a serviço público prestado por meio digital, sem necessidade de mediação humana), base nacional de serviços públicos (base de dados que contém as informações necessárias sobre a oferta de serviços públicos de todos os prestadores desses serviços) e plataformas de governo digital (ferramentas digitais e serviços comuns aos órgãos, normalmente ofertados de

classifica-brasil-entre-os-20-paises-com-melhor-oferta-de-servicos-publicos-digitais. Acesso em: jul., 2021.

32 BRASIL. Lei no 14.129, de 29 de março de 2021. Dispõe sobre princípios, regras e instrumentos para o Governo Digital e para o aumento da eficiência pública e altera a Lei no 7.116, de 29 de agosto de 1983, a Lei no 12.527, de 18 de novembro de 2011 (Lei de Acesso à Informação), a Lei no 12.682, de 9 de julho de 2012, e a Lei no 13.460, de 26 de junho de 2017. Disponível em: http://www.planalto.gov.br/ccivil_03/_Ato2019-2022/2021/Lei/L14129.htm. Acesso em: 05 abr. 2021. 
RECK, Janriê Rodrigues; HÜBNER, Bruna Henrique. A transformação digital do estado: digitalização do governo e dos serviços públicos no Brasil. Revista Eletrônica Direito e Política, Programa de Pós-Graduação Stricto Sensu em Ciência Jurídica da UNIVALI, Itajaí, v.16, n.3, 30 quadrimestre de 2021. Disponível em: www.univali.br/direitoepolitica - ISSN 1980-7791.

forma centralizada e compartilhada, necessárias para a oferta digital de serviços e de políticas públicas) ${ }^{33}$.

A prestação digital dos serviços públicos deve ocorrer por meio de tecnologias de amplo acesso pela população, inclusive pela de baixa renda ou residente em áreas rurais e isoladas, sem prejuízo do direito do cidadão a atendimento presencial, conforme o artigo $14^{34}$.

São princípios e diretrizes do Governo Digital e da eficiência pública, dentre outros a (i) disponibilização em plataforma única do acesso às informações e aos serviços públicos, possibilidade aos cidadãos, às pessoas jurídicas e aos outros entes públicos de demandar e de acessar serviços públicos por meio digital, sem necessidade de solicitação presencial; (ii) o uso de linguagem clara e compreensível a qualquer cidadão; a simplificação dos procedimentos de solicitação, oferta e acompanhamento dos serviços públicos, com foco na universalização do acesso e no autosserviço; (iii) permanência da possibilidade de atendimento presencial, de acordo com as características, a relevância e o públicoalvo do serviço; (iv) o estímulo a ações educativas para qualificação dos servidores públicos para o uso das tecnologias digitais e para a inclusão digital da população35.

Anterior ao sancionamento da Lei n. ${ }^{0}$ 14.129/2021, o Banco Interamericano de Desenvolvimento (BID) realizou a pesquisa de satisfação cidadã sobre os serviços

33 BRASIL. Lei no 14.129, de 29 de março de 2021. Dispõe sobre princípios, regras e instrumentos para o Governo Digital e para o aumento da eficiência pública e altera a Lei no 7.116, de 29 de agosto de 1983, a Lei no 12.527, de 18 de novembro de 2011 (Lei de Acesso à Informação), a Lei no 12.682, de 9 de julho de 2012, e a Lei no 13.460, de 26 de junho de 2017. Disponível em: http://www.planalto.gov.br/ccivil_03/_Ato2019-2022/2021/Lei/L14129.htm. Acesso em: 05 abr. 2021.

34 BRASIL. Lei no 14.129, de 29 de março de 2021. Dispõe sobre princípios, regras e instrumentos para o Governo Digital e para o aumento da eficiência pública e altera a Lei no 7.116, de 29 de agosto de 1983, a Lei no 12.527, de 18 de novembro de 2011 (Lei de Acesso à Informação), a Lei no 12.682, de 9 de julho de 2012, e a Lei no 13.460, de 26 de junho de 2017. Disponível em: http://www.planalto.gov.br/ccivil_03/_Ato2019-2022/2021/Lei/L14129.htm. Acesso em: 05 abr. 2021.

${ }^{35}$ BRASIL. Lei no 14.129, de 29 de março de 2021. Dispõe sobre princípios, regras e instrumentos para o Governo Digital e para o aumento da eficiência pública e altera a Lei no 7.116, de 29 de agosto de 1983, a Lei no 12.527, de 18 de novembro de 2011 (Lei de Acesso à Informação), a Lei no 12.682, de 9 de julho de 2012, e a Lei no 13.460, de 26 de junho de 2017. Disponível em: http://www.planalto.gov.br/ccivil_03/_Ato2019-2022/2021/Lei/L14129.htm. Acesso em: 05 abr. 2021. 
RECK, Janriê Rodrigues; HÜBNER, Bruna Henrique. A transformação digital do estado: digitalização do governo e dos serviços públicos no Brasil. Revista Eletrônica Direito e Política, Programa de Pós-Graduação Stricto Sensu em Ciência Jurídica da UNIVALI, Itajaí, v.16, n.3, 30 quadrimestre de 2021. Disponível em: www.univali.br/direitoepolitica - ISSN 1980-7791.

públicos digitais no Brasil, entre os meses de outubro e dezembro de 2020, com uma amostra da população brasileira de idade superior aos 16 anos de todo o território nacional ${ }^{36}$.

Ao serem questionados sobre a forma de acesso a serviços digitais públicos e privados, $87 \%$ responderam que acessam pelo telefone celular, $42 \%$ acessam pelo notebook ou computador, $5 \%$ acessam pelo tablet e $6 \%$ não sabem.

A proporção de pessoas que preferem ser atendidas por algum canal digital é de $60 \%$ (26\% via páginas de internet e $24 \%$ por celular), enquanto $24 \%$ reportou preferir o atendimento presencial. Observou-se que "Quanto maior a idade, mais alta a escolaridade formal e a renda, mais alta é a utilização das páginas de internet como principal meio para interagir com os governos" ${ }^{\prime 37}$.

Por sua vez, o atendimento presencial demonstrou ser a forma de atendimento preferida entre os menos adaptados ao mundo digital: a população de mais de 60 anos (34\%), as pessoas com menos escolaridade formal (28\%) e renda mais baixa $(31 \%)^{38}$.

Questionados acerca dos benefícios dos serviços públicos digitais ("O que os cidadãos brasileiros mais valorizam nos serviços públicos digitais?"), 46\% dos entrevistados responderam ser a economia de tempo e $29 \%$ destacaram a facilidade de poder ser atendido sem a necessidade de se deslocar até uma repartição pública ${ }^{39}$, conforme o gráfico abaixo:

36 LAFUENTE, Mariano; et al. Transformação digital dos governos brasileiros Satisfação dos cidadãos com os serviços públicos digitais. Banco Interamericano de Desenvolvimento, 2021. 37 LAFUENTE, Mariano; et al. Transformação digital dos governos brasileiros Satisfação dos cidadãos com os serviços públicos digitais. Banco Interamericano de Desenvolvimento, 2021, p. 24.

38 LAFUENTE, Mariano; et al. Transformação digital dos governos brasileiros Satisfação dos cidadãos com os serviços públicos digitais. Banco Interamericano de Desenvolvimento, 2021.

39 LAFUENTE, Mariano; et al. Transformação digital dos governos brasileiros Satisfação dos cidadãos com os serviços públicos digitais. Banco Interamericano de Desenvolvimento, 2021. 
RECK, Janriê Rodrigues; HÜBNER, Bruna Henrique. A transformação digital do estado: digitalização do governo e dos serviços públicos no Brasil. Revista Eletrônica Direito e Política, Programa de Pós-Graduação Stricto Sensu em Ciência Jurídica da UNIVALI, Itajaí, v.16, n.3, 30 quadrimestre de 2021. Disponível em: www.univali.br/direitoepolitica - ISSN 1980-7791.

\section{Principal benefício da oferta de serviços públicos de forma digital}

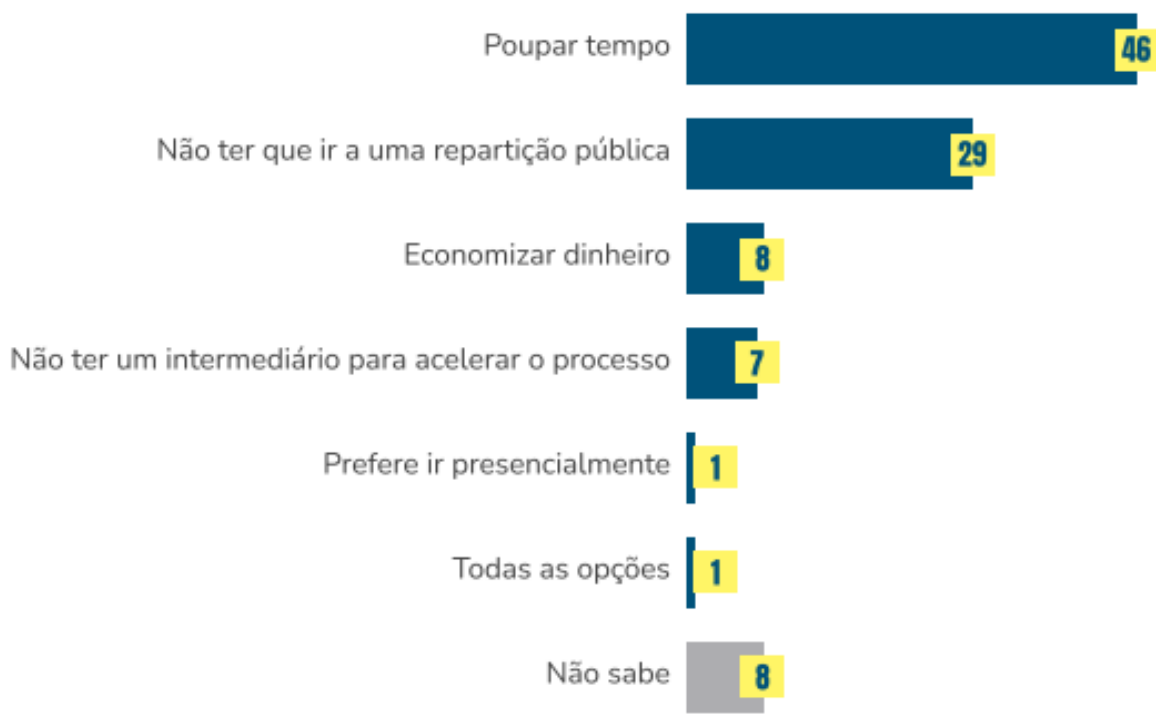

O grau de satisfação com a disponibilidade de serviços federais alcança $55 \%$ (com $14 \%$ de insatisfação e $31 \%$ neutros), é de 53\% em nível estadual (com 11\% de insatisfação e $36 \%$ neutros) e, nos casos dos serviços prestados por municípios, é de $54 \%$ ( $13 \%$ de insatisfação e $33 \%$ neutros $)^{40}$.

Também se destaca o grau de conhecimento do portal de serviços do governo federal, o Gov.Br (90\%), superior aos níveis registrados por demais serviços digitais do governo federal (70\%), dos governos estaduais (66\%) e dos municípios (56\%). O portal também registra baixo nível de insatisfação no uso, $11 \%{ }^{41}$.

Contudo, a satisfação com os serviços digitais privados é muito superior à dos serviços públicos: $35 \%$ dos entrevistados avaliaram os serviços digitais privados (última compra on-line) como muito bons, índice muito superior ao número de

40 LAFUENTE, Mariano; et al. Transformação digital dos governos brasileiros Satisfação dos cidadãos com os serviços públicos digitais. Banco Interamericano de Desenvolvimento, 2021.

41 LAFUENTE, Mariano; et al. Transformação digital dos governos brasileiros Satisfação dos cidadãos com os serviços públicos digitais. Banco Interamericano de Desenvolvimento, 2021, p. 28. 
RECK, Janriê Rodrigues; HÜBNER, Bruna Henrique. A transformação digital do estado: digitalização do governo e dos serviços públicos no Brasil. Revista Eletrônica Direito e Política, Programa de Pós-Graduação Stricto Sensu em Ciência Jurídica da UNIVALI, Itajaí, v.16, n.3, 30 quadrimestre de 2021. Disponível em: www.univali.br/direitoepolitica - ISSN 1980-7791.

pessoas que avaliaram como muito bons os serviços digitais oferecidos pelo governo federal $(5 \%)$ e pelos estados $(2 \%)$ e municípios $(4 \%)^{42}$.

Em conclusão, a pesquisa aponta que existem alguns grupos que apresentam menos capacidade de adaptação ao mundo digital: "as pessoas com mais de 60 anos, os indivíduos com baixa escolaridade formal e as pessoas com renda mais baixa. Esses grupos também acessam a internet principalmente pelo celular"43.

Nesse contexto, seria importante investir na melhoria da conectividade de banda larga, na disponibilidade de computadores e na alfabetização digital para esses grupos, a fim de superar a brecha digital no Brasil. A experiência do cidadãoconsumidor digital é mais bem avaliada do que a experiência de cidadão-usuário de serviços públicos digitais ${ }^{44}$

Considerando o impacto profundo das TICs na sociedade, possivelmente se caminha para uma nova forma de organização estatal, "que pode utilizar dessas comodidades de um modo que altere sua própria estrutura, essas tecnologias colocam os modelos tradicionais de governo eletrônico "ultrapassados"45.

Emerge, daí, a necessidade da administração mudar o foco da automação e redução de custos (presente na proposta de governo eletrônico) para enfatizar na co-criação com cidadãos e empresas. Este novo estágio de amadurecimento das tecnologias e seu emprego pelos governos é o símbolo da transformação para o governo digital ${ }^{46}$

42 LAFUENTE, Mariano; et al. Transformação digital dos governos brasileiros Satisfação dos cidadãos com os serviços públicos digitais. Banco Interamericano de Desenvolvimento, 2021.

43 LAFUENTE, Mariano; et al. Transformação digital dos governos brasileiros Satisfação dos cidadãos com os serviços públicos digitais. Banco Interamericano de Desenvolvimento, 2021, p. 40.

44 LAFUENTE, Mariano; et al. Transformação digital dos governos brasileiros Satisfação dos cidadãos com os serviços públicos digitais. Banco Interamericano de Desenvolvimento, 2021, p. 40.

45 VIANA, Ana Cristina Aguilar. Transformação digital na administração pública: do governo eletrônico ao governo digital. Revista Eurolatinoamericana de Derecho Administrativo, Santa Fe, vol. 8, n. 1, p. 115-136, ene./jun. 2021, p. 121.

46 VIANA, Ana Cristina Aguilar. Transformação digital na administração pública: do governo eletrônico ao governo digital. Revista Eurolatinoamericana de Derecho Administrativo, Santa Fe, vol. 8, n. 1, p. 115-136, ene./jun. 2021, p. 127. 
RECK, Janriê Rodrigues; HÜBNER, Bruna Henrique. A transformação digital do estado: digitalização do governo e dos serviços públicos no Brasil. Revista Eletrônica Direito e Política, Programa de Pós-Graduação Stricto Sensu em Ciência Jurídica da UNIVALI, Itajaí, v.16, n.3, 30 quadrimestre de 2021. Disponível em: www.univali.br/direitoepolitica - ISSN 1980-7791.

Entre as principais vantagens da digitalização dos processos e serviços prestados pelo governo pode-se destacar: atendimento da crescente demanda social; economicidade; maior centralização de serviços e menor fragmentação do governo nas relações com o cidadão; segurança e privacidade; transparência e controle social e qualidade na prestação de serviços.

Ainda, Cristóvam; Saikali; Sousa ${ }^{47}$ destacam a importância que a utilização de TICs possuem na concretização de direitos sociais, pela prestação direta de serviços públicos, avançando para a noção de Governo digital.

Contudo, não como discutir serviço público digital no Brasil sem levar em consideração a desigualdade ao acesso da internet no país. Segundo dados da Estratégia Brasileira para a Transformação Digital (E-Digital), enquanto a quantidade de brasileiros acessando a Internet venha aumentando substancialmente nos últimos anos, a proporção de usuários que fazem uso efetivo de serviços de governo online mantém-se constante ${ }^{48}$

No mesmo sentido, a Organização para a Cooperação e Desenvolvimento Econômico (OCDE) identificou em Relatório de estudos sobre a transformação digital no Brasil problemas de infraestrutura e desconexão dos serviços prestados ${ }^{49}$

A transformação digital no país, neste trabalho abordada a partir dos serviços públicos digitais e do Governo digital, enfrenta diversos desafios, como entre a falta de acesso ou o acessado inadequado a tecnologias por considerável parcela da população brasileira, a necessidade de incorporação das TICs no âmbito

47 CRISTÓVAM, José Sérgio da Silva; SAIKALI, Lucas Bossoni; SOUSA, Thanderson Pereira de. Governo Digital na Implementação de Serviços Públicos para a Concretização de Direitos Sociais no Brasil. Sequência, Florianópolis, n. 84, p. 209-242, abr. 2020. DOI: 10.5007/21777055.2020v43n89p209.

48 BRASIL. Estratégia brasileira para a transformação digital (E-Digital). Brasília, 2018.

49 VIANA, Ana Cristina Aguilar. Transformação digital na administração pública: do governo eletrônico ao governo digital. Revista Eurolatinoamericana de Derecho Administrativo, Santa Fe, vol. 8, n. 1, p. 115-136, ene./jun. 2021. 
RECK, Janriê Rodrigues; HÜBNER, Bruna Henrique. A transformação digital do estado: digitalização do governo e dos serviços públicos no Brasil. Revista Eletrônica Direito e Política, Programa de Pós-Graduação Stricto Sensu em Ciência Jurídica da UNIVALI, Itajaí, v.16, n.3, 30 quadrimestre de 2021. Disponível em: www.univali.br/direitoepolitica - ISSN 1980-7791.

administrativo e a abertura do gestor público ao experimentalismo nas ações públicas $^{50}$.

A Lei n. ${ }^{0}$ 14.129/2021 pode ser vista como importante forma de concretização da Estratégia de Governo Digital para o período de 2020 a 2022. A digitalização dos serviços públicos e do governo, se desenvolvida em observância aos princípios e objetivos da Estratégia de Governo Digital, sem também olvidar daquela parcela da população denominada de "excluídos digitais", tem potencial para qualificar a prestação do serviço público, possibilitando uma universalização ainda maior e fomentando a interação entre a administração pública e o cidadão-usuário de serviços públicos digitais.

\section{CONSIDERAÇÕES FINAIS}

A transformação digital vem acompanhada de desafios, e no Brasil, possivelmente a de maior relevância é $s$ desigualdades no acesso ao universo digital se evidenciam. A própria concretização da Estratégia de Governança Digital (EGD) proposta pelo governo apresenta dificuldades de inserção, segundo a Organização para a Cooperação e Desenvolvimento Econômico (OCDE).

O Governo digital não se restringe à automação de processos e a disponibilização de serviços públicos on-line, busca avançar para um modelo de administração pública capaz de integrar as TICs a seus processos internos e aos cidadãos, buscando cumprir os papeis essenciais do Estado de forma mais eficiente, bem como restar serviços públicos mais qualificados.

Para a OCDE o atual estágio de emprego das tecnologias digitais e seu emprego pelos governos, marca a mudança de paradigma de governo eletrônico para

50 CRISTÓVAM, José Sérgio da Silva; SAIKALI, Lucas Bossoni; SOUSA, Thanderson Pereira de. Governo Digital na Implementação de Serviços Públicos para a Concretização de Direitos Sociais no Brasil. Sequência, Florianópolis, n. 84, p. 209-242, abr. 2020. DOI: 10.5007/21777055.2020v43n89p209. 
RECK, Janriê Rodrigues; HÜBNER, Bruna Henrique. A transformação digital do estado: digitalização do governo e dos serviços públicos no Brasil. Revista Eletrônica Direito e Política, Programa de Pós-Graduação Stricto Sensu em Ciência Jurídica da UNIVALI, Itajaí, v.16, n.3, 30 quadrimestre de 2021. Disponível em: www.univali.br/direitoepolitica - ISSN 1980-7791.

governo digital, onde as TICS passam a ser elemento central da transformação do setor público, possibilitando aos usuários que possam.

No Brasil, em 2016 foi instituída a Estratégia de Governança Digital (EGD), que foi atualizada em 2020. Propõe a promoção do uso pelo setor público de recursos de tecnologia da informação para melhorar a disponibilização de informação, incentivar a participação da sociedade no processo de tomar de decisão e aprimorar o nível de transparência e efetividade do governo federal. O Decreto no 10.332, publicado no dia 29 de abril de 2020, instituiu a Estratégia de Governo Digital para o período de 2020 a 2022, no âmbito dos órgãos e das entidades da administração pública federal direta, autárquica e fundacional e dá outras providências.

Considerando os dados da pesquisa de satisfação cidadã sobre os serviços públicos digitais no Brasil, realizada pelo Banco Interamericano de Desenvolvimento (BID), a satisfação com os serviços digitais privados é muito superior à dos serviços públicos, o que aponta para a necessidade de um diagnóstico, pelo governo e em conjunto com o cidadão-usuário, de como tornar a prestação de serviços públicos digitais mais qualificada.

A Lei n. ${ }^{14}$ 14.129/2021 pode ser vista como importante forma de concretização da Estratégia de Governo Digital para o período de 2020 a 2022. A digitalização dos serviços públicos e do governo, se desenvolvida em observância aos princípios e objetivos da Estratégia de Governo Digital, sem também olvidar daquela parcela da população denominada de "excluídos digitais", tem potencial para qualificar a prestação do serviço público, possibilitando uma universalização ainda maior e fomentando a interação entre a administração pública e o cidadão-usuário de serviços públicos digitais.

\section{REFERÊNCIAS DAS FONTES CITADAS}

BRASIL. Tribunal de Contas da União. Política pública de inclusão digital/Tribunal de Contas da União, Brasília: TCU, SeinfraAeroTelecom, 2015. 
RECK, Janriê Rodrigues; HÜBNER, Bruna Henrique. A transformação digital do estado: digitalização do governo e dos serviços públicos no Brasil. Revista Eletrônica Direito e Política, Programa de Pós-Graduação Stricto Sensu em Ciência Jurídica da UNIVALI, Itajaí, v.16, n.3, 30 quadrimestre de 2021. Disponível em: www.univali.br/direitoepolitica - ISSN 1980-7791.

\section{BRASIL. Estratégia brasileira para a transformação digital (E-Digital).} Brasília, 2018.

BRASIL. Governo eletrônico: ONU classifica Brasil entre os 20 países com melhor oferta de serviços públicos digitais. Publicado em 21 jul. 2020. Disponível em: https://www.gov.br/casacivil/pt-br/assuntos/noticias/2020/julho/governoeletronico-onu-classifica-brasil-entre-os-20-paises-com-melhor-oferta-deservicos-publicos-digitais.

BRASIL. Lei no 14.129, de 29 de março de 2021. Dispõe sobre princípios, regras e instrumentos para o Governo Digital e para o aumento da eficiência pública e altera a Lei no 7.116, de 29 de agosto de 1983, a Lei no 12.527, de 18 de novembro de 2011 (Lei de Acesso à Informação), a Lei no 12.682, de 9 de julho de 2012, e a Lei no 13.460, de 26 de junho de 2017. Disponível em: http://www.planalto.gov.br/ccivil_03/_Ato2019-2022/2021/Lei/L14129.htm. Acesso em: 05 abr. 2021.

BRASIL. Decreto no 9.319, de 21 de março de 2018. Institui o Sistema Nacional para a Transformação Digital e estabelece a estrutura de governança para a implantação da Estratégia Brasileira para a Transformação Digital. Disponível em:http://www.planalto.gov.br/ccivil_03/_Ato20152018/2018/Decreto/D9319.htm. Acesso em: jul. 2021.

BRASIL. Decreto no 10.332, de 28 de abril de 2020. Institui a Estratégia de Governo Digital para o período de 2020 a 2022, no âmbito dos órgãos e das entidades da administração pública federal direta, autárquica e fundacional e dá outras providências. Disponível em:

http://www.planalto.gov.br/ccivil_03/_ato2019-2022/2020/decreto/D10332.htm. Acesso em 09/01/21.

GOV.BR. 2020. OCDE classifica Brasil em $16^{\circ}$ no ranking internacional de governo digital. Notícias. Casa Civil, out. 2020. Disponível em: https://www.gov.br/casacivil/pt-br/assuntos/noticias/2020/outubro/ocdeclassifica-brasil-em-16o-no-ranking-internacional-de-governo-digital. Acesso em: jul., 2021.

BRASIL. Estratégia de Governo Digital 2020-2022. Governo Digital. Disponível em: https://www.gov.br/governodigital/pt-br/EGD2020. Acesso em: jul. 2021.

\section{BUCCI, Maria Paula Dallari. Fundamentos para uma Teoria Jurídica das} Políticas Públicas. São Paulo: Saraiva, 2013.

CASTELLS, Manuel. A sociedade em rede - A era da informação: economia, sociedade e cultura. 8 ed. rev. e ampl. Tradução: Roneide Venâncio Majer. São Paulo: Paz e Terra, 2005.

CRISTÓVAM, José Sérgio da Silva; SAIKALI, Lucas Bossoni; SOUSA, Thanderson Pereira de. Governo Digital na Implementação de Serviços Públicos para a 
RECK, Janriê Rodrigues; HÜBNER, Bruna Henrique. A transformação digital do estado: digitalização do governo e dos serviços públicos no Brasil. Revista Eletrônica Direito e Política, Programa de Pós-Graduação Stricto Sensu em Ciência Jurídica da UNIVALI, Itajaí, v.16, n.3, 30 quadrimestre de 2021. Disponível em: www.univali.br/direitoepolitica - ISSN 1980-7791.

Concretização de Direitos Sociais no Brasil. Sequência, Florianópolis, n. 84, p. 209-242, abr. 2020. DOI: 10.5007/2177-7055.2020v43n89p209.

GOV.BR. 2020. Governo eletrônico: ONU classifica Brasil entre os 20 países com melhor oferta de serviços públicos digitais. Notícias. Casa Civil, jul., 2020. Disponível em:https://www.gov.br/casacivil/pt-

br/assuntos/noticias/2020/julho/governo-eletronico-onu-classifica-brasil-entreos-20-paises-com-melhor-oferta-de-servicos-publicos-digitais. Acesso em: jul., 2021.

LAFUENTE, Mariano; et al. Transformação digital dos governos brasileiros Satisfação dos cidadãos com os serviços públicos digitais. Banco Interamericano de Desenvolvimento, 2021.

OCDE. Digital Government Review of Brazil: Towards the Digital Transformation of the Public Sector. OECD Digital Government Studies, OECD Publishing, 2018, Paris, Disponível em:

https://doi.org/10.1787/9789264307636-en. Acesso em: jul. 2021.

VIANA, Ana Cristina Aguilar. Transformação digital na administração pública: do governo eletrônico ao governo digital. Revista Eurolatinoamericana de Derecho Administrativo, Santa Fe, vol. 8, n. 1, p. 115-136, ene./jun. 2021.

WEISS, Marcos Cesar. Sociedade sensoriada: a sociedade da transformação digital. Estudos Avançados [online]. 2019, v. 33, n. 95. Disponível em: https://doi.org/10.1590/s0103-4014.2019.3395.0013.ISSN 1806-9592.Acesso em 09 ago 2021. 